\title{
Agricultural Risk Pricing in Senegal
}

\author{
Allé Nar Diop \\ Faculty of Economics and Management, University Cheikh Anta Diop, Dakar, Senegal \\ Email: alndiop@hotmail.com
}

How to cite this paper: Diop, A.N. (2019) Agricultural Risk Pricing in Senegal. Journal of Mathematical Finance, 9, 182-201. https://doi.org/10.4236/jmf.2019.92010

Received: March 22, 2019

Accepted: May 12, 2019

Published: May 15, 2019

Copyright @ 2019 by author(s) and Scientific Research Publishing Inc. This work is licensed under the Creative Commons Attribution International License (CC BY 4.0).

http://creativecommons.org/licenses/by/4.0/

\begin{abstract}
The purpose of this article is to determine the pure premium to be paid by the Senegalese farmer insured at conventional risks. Using the general linear model (GLM), the frequency and severity of different types of risks to farmers were determined. They depend positively on the type of risk and the parameters of the estimated models are all significant. We have shown that the health risks, locusts (wild locusts), wild animals and ducks have higher claims than climatic events (rainfall deficit, floods). Health risks, floods and rainfall deficits are extreme phenomena whose probability of achievement is low. This explains the low premiums of these risks. For better pricing, the insurance company will need to consider the type of risk to which each insured is most exposed and determine the corresponding premium. This segmentation will determine the correct premium.
\end{abstract}

\section{Keywords}

Risk, Premium, Loss, Pricing

\section{Introduction}

The role of agriculture as the main engine of economic growth in Senegal has made this sector, since the 1980s, a priority in the various strategic documents of economic policies that have succeeded one another. Thus, there have always been questions in the various economic policy strategies, to make the agricultural sector efficient enough to develop the rural world and bring economic growth.

The long-term vision in the agricultural sector is defined by the Agro-SylvoPastoral Orientation Law (ASPO) developed for the period 2004-2024 and which bases the agro-sylvo-pastoral development policy constitutes the basis of the development and implementation of operational programs. Ninety five percent (95\%) of agriculture production depends on rainfall conditions. Overwintering is often characterized by late settlement, poor spatial and temporal distribution, and early rains in many parts of the country. In addition, the rainy season is rel- 
atively short in Senegal, 3 to 4 months in the year (for an average of about 600 $\mathrm{mm} / 70$ days), which is a major constraint to agricultural practices based on the availability of water. The consequence is that cereal production and industrial crops are very erratic. The results of agricultural campaigns in Senegal are characterized by instability of production even though it has experienced significant leaps.

This situation hides very large disparities from one zone to another. Pastures have also been affected, particularly in the northern regions of the country (Saint-Louis and Louga). The agricultural sector is therefore confronted with a multitude of risks, among which those related to climate hazards, sanitary and phytosanitary diseases and market fluctuations.

In this context, the challenge is to pursue the implementation of the strategic guidelines in terms of protection, in particular: risk control, preventive management of water resources, the dissemination of good farming practices, the integration of adaptation to climate change in agricultural projects, the pursuit of the establishment of an agricultural insurance system, and this by adopting a differentiated approach, adapted to each production sector and aimed as much at producing productive and productive agriculture as solidarity farming.

The problematic of the effects of climate change and the possible multiplication of unusual climatic disorders, reinforce the need to improve farm protection mechanisms against hazards by setting up agricultural insurance. Agricultural insurance is insurance against one or more of the following losses: 1) the loss of production of designated agricultural products resulting from one of the designated risks; 2) the loss suffered when seeding or planting is prevented by one of the designated risks; 3 ) the loss of designated agricultural products resulting from one of the designated risks; 4) loss of income from designated agricultural products resulting from a designated risk; 5) any regulatory loss.

The National Company of Agriculture Insurance of Senegal (NCAIS) uses index insurance and its objectives include: reducing farmers' vulnerability to hazards, increasing agricultural production and food security and stabilizing and growing farmers' incomes.

Index insurance is a relatively innovative insurance approach that compensates for asset losses or working capital losses primarily on the basis of a pre-determined index (for example, the level of rainfall). This, as a result of bad weather or natural disasters, without requiring the use of traditional services of experts in claims assessment. Before the start of the insurance period, a statistical index is developed to measure deviations from normal by parameters such as precipitation, temperature, magnitude of earthquake, speed of crop yield or livestock mortality rates.

The insurance systems against calamities rely for the most part on an index. They only cover one or more risks that can lead to a bad harvest, and the compensation of the insured depends on an objective trigger that is easy to follow. Many are insurance systems against excess and bad weather rather than direct 
compensation for the actual loss of a farmer in terms of crop failure or loss of property.

An important problem facing the insurer is pricing. It is even more important that after 10 years of experience, NCAIS has recorded a large amount of information on the behavior of these subscribers. Experimenting with other rainfall indices on existing products or on new products or the application of experience-based pricing will allow each risk to be assigned a fair and equitable premium. This premium for a period depends solely on the (unknown) loss distribution of this risk for the period [1].

The main purpose of this article is to determine the pure premium according to the nature of the claim. To achieve this goal, cost and frequency modeling using the general linear model will be adopted.

This article is divided into three sections: the first is devoted to the literature review on agricultural insurance, the second the source of the data, the third to the methodological framework and the fourth to the econometric estimation and interpretation of the results.

\section{Literature Reviews}

Agricultural insurance has existed for centuries in different forms. Western European farmers began in the 17th century to form mutual private insurance and mutual insurance companies. At the end of the nineteenth century until the beginning of the twentieth century, mutual private hail insurance spread to the United States, Canada and Argentina. Similar programs have begun to develop in Latin America (Brazil, Costa Rica, Ecuador and Mexico) and Asia (India and the Philippines) from the 1950s to the 1980s, but most public sector programs in Latin America bad results.

Agricultural insurance is growing strongly. The World Bank attributes this growth in part to the fact that these products respond to the systemic nature of agricultural production losses, such as widespread drought. Since the 1990s, a number of products have been tested around the world. In some countries, indexed products have not gone beyond the pilot stage, but other countries (Mexico and India) have established well-established programs. Insurance products based on indices are available in Africa.

[2] theoretically and empirically analyzed crop insurance with yields per hectare using the linear additive model of western Kentucky soybean producers. In the linear additive model, it shows the relationship between the average yield of the individual producer (dependent variable) and the average yield of a surrounding geographical area (independent variable) and a random error term not correlated with aggregate area yield. The linear additive model breaks down the individual yield into a systematic component that is perfectly correlated with the yield of the area and a non-systematic component that is not correlated with the yield per hectare. Before the crop insurance program on regional yields, the individual yield crop insurance program was introduced in agriculture. In this 
case, the individual crop insurance program benefit is paid to the insured on their own loss of yield. In the individual crop insurance program, three important issues arise; namely adverse selection, moral hazard and high administrative cost. These problems weaken the actuarial performance of the crop insurance program and do not attract a large number of farmers. In this situation, Miranda offers crop insurance based on the performance of the zone of acceptance. In this insurance program, in the insured zone, farmers receive the same amount of compensation per insured hectare because of crop losses and pay the same premium to the insurer.

The regional yield crop insurance program significantly reduces adverse selection problems and significantly reduces administrative costs and finally eliminates moral hazard issues. He emphasized that regional crop insurance is an important tool for risk reduction in agricultural insurance policy.

[3] studied "Crop Insurance and Disaster Assistance Design for Wheat and Cereal Sorghum" (name of crop). In this study, they compared the effectiveness of two crop insurance models, two disaster assistance models, crop insurance, and a government product programmed to reduce the risk of net return of sorghum a region of uniform production in south-central Kansas and for wheat operations in a less uniform production area in northwestern Kansas. They use the stochastic dominance analysis of the net income distribution to identify where the preferences are at multiple risk intervals. For this reason, they examined six strategies: a) participation in the government-only commodity program (GCP), b) participation in the government commodity program and the purchase of individual crop insurance $(\mathrm{GCP}+\mathrm{CI})$; government commodity program and purchase of regional crop insurance $(\mathrm{GCP}+\mathrm{ACI})$; d) Participating in a Government-linked Compensation/Crop Insurance (LDC) Program: e) Participating in the Government's Commodity Program and Assistance in an Individual Disaster Assistance Program (GCP) + DIS); and f) participation in the Government's Commodity Program and the receipt of the Disaster Assistant in a Regional Disaster Assistance Program (GCP + ADIS).

Empirical analysis shows that wheat and sorghum producers would prefer a crop insurance or disaster assistance program in addition to the government's commodity program. They also mentioned that disaster assistance is better than taking out a crop insurance policy.

Risk-averse managers of grain sorghum in south-central Kansas and northwestern Kansas prefer individual crop insurance instead of regional crop insurance to produce crops with relatively higher risk yields. On the other hand, farmers growing low-risk crops (wheat) in south-central Kansas are more likely to prefer zone crop insurance. If adverse selection and moral hazard continue to be a problem for the individual crop insurance program, a subsidized regional crop insurance plan could be an alternative. In fact, the crop insurance system of the subsidized zones would prevent moral hazard and reduce the problems of adverse selection. Here again, farmers prefer the preferred risk of crop insurance 
from the region to the individual crop. For a higher level of subsidy, less riskprone farmers prefer crop insurance rather than full-cost individual crop insurance.

[4] examines the impact of crops on non-life insurance consumption. It uses economic, institutional and cultural variables from 82 countries over a 10-year period. Using bootstrap techniques, it shows that the weakest nations, with a high level of individualism and a high degree of uncertainty avoidance tend to have a high level of non-life insurance consumption. Empirical results suggest that consumers can respond to insurance solicitations based on their cultural belief, and not and their economic rationalities alone.

[5] find that the barriers to insurance are lack of respect for economic frameworks, problems in the statistical system, lack of competition in the service sector, and lack of monitoring and evaluation. In addition, they found the threats that insurers face: they are inappropriate production entities, degraded lands, the lack of production standards and the existence of poor operating systems.

[6] [7] are the most comprehensive and recent studies on crop insurance and land use issues in the United States. They use a combination of econometric and simulation techniques and improve the earlier literature by focusing on marginal lands (a critical part of the northern plains that comprise much of the Prairie Basin region). By distinguishing between converted grassland types and using field data rather than county-level data. Their findings are consistent with previous literature that the effect of subsidized crop insurance in marginal land cropping is statistically significant but low at less than 1 percent.

In particular, [7] estimate that the effect of crop prices is much larger than Crop Insurance subsidies on marginal land conversion. They find that a 5\% decrease in the crop insurance premium subsidy rate results in $0.6 \%$ of insured cropland being converted to non-cropland. While a $5 \%$ decrease in crop prices results in the conversion of $1.01 \%$ of cropland insured to non-cropland.

Beyond the weak expansionary effect on conversion of grassland to cropland, crop insurance has offsetting effects on cropland in the form of less use of other risk-reduction strategies, such as intensive chemicals. Empirical results from the Great Plains suggest that farmers who purchase crop insurance use fewer chemical inputs [8]. Similar results were obtained in [9] for Iowa corn. [8] [9] refuted the contradictory results of the earlier study by [10]. [8] concluded that environmental consequences should not be the basis of efforts to persuade legislators to terminate the crop insurance program.

[11] in his study on "The Performance of Nigerian Food Crop Producers in Imo State, South-East Nigeria", they Evaluate the Production Performance of Food Crops of Farmers Who Have Adopted the Crop Production Regime. Agricultural insurance introduced in 1984 and the influence of socio-economic characteristics on farmers' production. Primary and secondary data were used in the study. Primary data were obtained from 77 food crop producers selected by simple random sampling from a list of 145 farmers under the Imo State Insurance Scheme. The Z-test and the multiple regression model were used to determine 
the impact and influence of socio-economic characteristics such as age, agricultural experience, education, etc. on farmers' production, respectively. The Z-test of the impact of the program on farmers 'production showed that there was a significant change in farmers' output after insurance. The results of the analyzes of the socio-economic characteristics of the farmers interviewed showed that the majority $(66.23 \%)$ of the sampled farmers are men. It also showed that the majority $(46.75 \%)$ of sampled farmers were in the 41 to 50 age group. In addition, more than $70 \%$ of insured farmers had secondary and higher education. The Z-test showed that farmers' agricultural production had increased after the application of the insurance scheme.

Average agricultural production was 16.01 metric tons before insurance but 21.66 metric tons after insurance. Multiple regression analysis on the influence of socio-economic characteristics of agricultural production after insurance has shown that the level of education, agricultural experience, farm size and number of technologies used in farm are significant variables while age, sex, and household size are insignificant. The study therefore recommends redoubling efforts to sensitize producers on the laudable objectives of the food crop insurance scheme (particularly in the quest for food security by the nation.

[12] in their study entitled "Mathematical Modeling for Crop Insurance Premium Estimate: Case Study of Total Equal Premium Compensation" construct a mathematical model to estimate the premium of crop insurance for the case of full compensation for damages. They are also studying relief provided by the Thai government to farmers who have experienced floods. The scope of this research is a crop insurance covering damage caused by floods. The result shows that the expected insurance cost (premium) for each farmer household could be calculated by the product of an expected compensation value for each flood and a projected number of claims.

[13] analyze the willingness to pay for cocoa price insurance in Ghana in the cocoa industry using the contingent valuation method on data collected from 201 cocoa farmers in Bibiani-Anhiawso-Bekwai District, Ghana. A constrained model is used to determine the factors influencing farmers' adoption of cocoa price insurance and the premiums that farmers are willing to pay. Empirical results of the study reveal that farmers' interest in cocoa price insurance was affected by the variety of explanatory variables such as marital status, number of years of cocoa culture, level of education, household size, farm size, ownership of farmland for agriculture, age of cocoa plantation, age squared of cocoa plantation, farmers aware of insurance scheme and income of the cocoa farm. On the other hand, the premium that farmers were willing to pay is heavily influenced by marital status, achievements, use of farmland for agricultural purposes, raising farmers' awareness of the insurance scheme. On average, cocoa farmers are willing to pay between $9.3 \%$ and $10.5 \%$ of the value of the option they intend to receive as a bonus based on value. The study recommends paying particular attention to farmer insurance education.

[14] analyze performance gaps in the context of crop insurance. They estab- 
lish an asymmetric information indicator and evaluate the possible influence of asymmetrical information on the decision of Spanish wheat producers to take out an insurance policy. The analysis includes simulated performance using a validated culture model. The results suggest that accuracy in determining assured yield is critical in farmers' decision to contract crop insurance as part of broader coverage. Historical insurance data, when available, provides a stronger technical basis for evaluating and calibrating insurance parameters against simulated data, using crop models. Nevertheless, the use of crop models can be useful for designing new insurance formulas in the absence of historical data or for assessing scenarios of expected changes. In this case, it is suggested that yield differentials be estimated and taken into account when using simulated achievable returns.

[15] examine the effects of weather and insurance on net crop income using the instrumental variable regression approach on a Ricardian model. The study identifies the factors influencing the purchase of insurance by farmers using a probit model. The data from the study were collected from a representative sample of farmers in three selected South African provinces. The results indicated that having insurance, the number of workers employed, the size of irrigated farmland and precipitation had significant effects on net income. It was also revealed that the experience, illustrated by years of exploitation and income, had influenced the adoption of insurance by farmers. As a result, they advocate the establishment of efficient irrigation facilities and the promotion of insurance to farmers.

\section{The Theoretical Model, the Source of the Data, the Definition of the Variables and the Specification of the Model}

\subsection{The Model of the Cumulative Amount of Claims}

Define abbreviations and acronyms the first time they are used in the text, even after they have been defined in the abstract. In practice, an insured can be at the origin of 0 , one or more of claims. Note $Y_{i j}$ the cost of the insured's first claim, $X_{i}$ the annual charge for the insured, and $K_{i}$ the number of claims for this insured.

$$
X_{i}=Y_{i 1}+Y_{i 2}+\cdots+Y_{i K_{i}}
$$

The number $K_{i}$ is a random variable and the costs $Y_{i j}$ are also random variables. The total random charge for the insurer is the sum of the losses attributable to each policyholder. We can stop looking at the identification of claims specific to each insured by asking:

$$
N_{s}=K_{1}+K_{2}+\cdots+K_{n a}
$$

where na represent the number of insured. We can then rewrite:

$$
\sum_{i \leq n a} X_{i}=\sum_{i \leq n a} \sum_{j \leq K_{i}} Y_{i 1}=\sum_{i \leq N_{s}} Y_{l}
$$

By renumbering the claims, leaving aside the insured who gave them birth. 
Subject to making two assumptions, the expectation and variance of the claim burden can be calculated.

\subsubsection{The Assumptions of the Model}

Two hypotheses are formulated: the first on the independence and the stationarity of the costs of disaster and the second on the independence of the frequencies and the costs.

\section{Hypothesis 1: Independence and stationarity of claims costs}

The random variables $Y_{i j}$ are independent and identically distributed (iid). This hypothesis requires that discounted values (by a carefully chosen rate of "inflation") be considered for the amounts of claims observed over long periods.

\section{Hypothesis 2: Frequency-cost independence}

The common distribution of $Y_{i j}$ does not depend on the value taken by $K_{i}$. This assumption is not always verified in reality (hence the interest of the tariff zones which "decorrelate" frequency and cost of claims).

\subsubsection{The Parameters of the Model}

The hypotheses set out above make it possible to obtain interesting properties of expectancy and variance:

- Expectation of the loss burden

The pure premium is given by the following formula:

Pure premium $=$ Total charge $/ \mathrm{NbContracts}$

$$
E(X)=E(K) \cdot E(Y)
$$

What is often expressed, for a contract, by pure premium = frequency $\mathrm{x}$ average cost.

- Variance of the claim burden

$$
V(X)=E(K) \cdot V(Y)+V(K) \cdot E^{2}(Y)
$$

\subsection{The Generalized Linear Model}

The purpose of this section is to predict the frequency/claim load $(N / Y)$ for a client. The methodology used consists in finding the link between $(N$ or $Y)$ with the explanatory variables available at the level of the database. In other words, find the linear predictor $\beta\left(\beta_{1}, \beta_{2}, \cdots, \beta_{p}\right)$ that corresponds to the following relation:

$$
E(N / X)=\mu=g^{-1}(X \beta)
$$

\subsubsection{Constructive Assumptions for the Application of Linear Regression}

The estimation of the conditional expectation of the frequency or the load amounts to identifying the function $\varphi$ such that:

$$
\begin{gathered}
E(N / X=x)=\varphi(x) \\
N=\varphi\left(X_{1}, X_{2}, \cdots, X_{p}\right)+\varepsilon
\end{gathered}
$$

where: 


$$
\varphi: R_{p} \rightarrow R
$$

This writing assumes a linear model. This assumption comes from the fact that the estimation of a function on $R_{k}$ is too complex numerically. However, the behavior of the frequency and the burden of the incident is not linear. The costs of claims, for example, when they materialize, follow a very asymmetrical density clearly non-Gaussian. Often, the data also show a constant coefficient of variation $\sigma / \mu$ rather than a constant variance (fundamental property in the linear model).

\subsubsection{Authorized Laws and Restoration of Linearity}

Generalized linear models are an extension of the Gaussian linear model, obtained by allowing other (conditional) laws than the Gaussian law. The GLM theory has an advantage over classical linear models: the normal character of the variable to be explained is no longer imposed as well as the normality of the distributions of the residues. Only membership in an exponential family is essential. Let $Y$ be the Random variable to explain with, $\mu=E(N / X=x)=\varphi(x)$, the linear predictor consisting of a linear function of the explanatory variables $X$.

$$
\varphi=\left(X_{1}, X_{2}, \cdots, X_{p}\right)=X \beta
$$

We then need a link function $g$ to establish the linear link between $\mu$ and the explanatory variables $X$ :

$$
\begin{gathered}
g(\mu)=\varphi=\left(X_{1}, X_{2}, \cdots, X_{p}\right) \\
f_{Y}\left(y_{i}, \theta_{i}, \phi\right)=\exp \left\{\left(y_{i} \cdot \theta_{i}-b\left(\theta_{i}\right)\right) / a(\phi)+c\left(y_{i}, \phi\right)\right\}
\end{gathered}
$$

With $a(\cdot), b(\cdot)$ and $c(\cdot)$ specific functions. The parameter $\theta$ is called the natural parameter of the exponential family. The parameter $\varphi$ is called the dispersion parameter. This is a nuisance parameter that does not depend on $y_{i}$ observation. This formulation includes most of the usual laws with one or two parameters: Gaussian, inverse Gaussian, gamma, Poisson, binomial...., replacing $\theta, \varphi, a($.$) ,$ $b($.) And $c$ (.) By the parameters of these laws as follows: (Table 1).

Table 1. Authorized laws.

\begin{tabular}{ccccc}
\hline Distribution & $\theta_{i}$ & $b\left(\theta_{i}\right)$ & $\phi$ & $\mu_{i}$ \\
\hline Bernoulli & $\ln \left(\frac{\pi_{i}}{1-\pi_{i}}\right)$ & $\ln \left(1+\exp \left(\theta_{i}\right)\right)$ & 1 & $\pi_{i}=\frac{\exp \left(\theta_{i}\right)}{1+\exp \left(\theta_{i}\right)}$ \\
Poisson & $\ln \left(\lambda_{i}\right)$ & $\exp \left(\theta_{i}\right)$ & 1 & $\exp \left(\theta_{i}\right)=\lambda_{i}$ \\
Normal & $\mu_{i}$ & $\frac{\theta_{i}^{2}}{2}$ & $\sigma^{2}$ & $\theta_{i}=\mu_{i}$ \\
Gamma & $-\frac{1}{\mu_{i}}$ & $-\frac{1}{\mu_{i}}$ & $\frac{1}{v}$ & $-\frac{1}{\theta_{i}}=\mu_{i}$ \\
Inverse & $-\frac{1}{2 \mu_{i}^{2}}$ & $-\left(-2 \theta_{i}\right)^{1 / 2}$ & $\sigma^{2}$ & $\frac{1}{\left(-2 \theta_{i}\right)^{1 / 2}}=\mu_{i}$ \\
Gaussian & & & &
\end{tabular}




\subsubsection{Restoring Linearity: Link Function}

Now that $N$ or $Y$ can follow any exponential law, we need an appropriate link function $g$ that can link them to a linear predictor. There are several link functions, the ones we use frequently is the canonical link function. That is to say the function $g$ which makes it possible to relate the expectation to the natural parameter $\theta \cdot g(\mu)=\theta$. Each of the laws of the exponential family has its own canonical bonding function.

\subsection{Data Source}

The primary source of data that we have available to model risks, and build a segmented tariff is the base formed from the information collected in the subscription forms. The data on the insured persons come from the National Company of Agricultural Insurance, they are stored in a base called "Slip of claims". They are observed over two years (2016 to 2017) and concerns 491 insurance companies. The variables are: Policy number: this field will link the "insured" database with that of the contracts as well as that of the claims. The customer number "customer number": it corresponds to the customer reference assigned to the subscription of the contract. The use of this variable will be important because it will make it possible to erase duplicates and to avoid counting twice the same person in our study (this will be our primary key). The registration number "registration number" allows you to follow the order in which customers have subscribed to an insurance policy. The effective date is the date from which the contract takes effect. The due date is when the contract ends. The region variable includes the 14 regions of Senegal; the Department (Depart) comprises the 44 departments of Senegal, the common variable and rural community determines the public authority or the subscriber of the insurance policy resides and where is located the insured property. The insured variable gives the natural person or the group having subscribed to a policy. The variable "Invoice" materializes the number of the customer's invoice following the payment of the premium. The variable "branch" gives the branch in which the insurance policy is taken out, it comprises 4 modalities: harvest, breeding, poultry, equipment. The variable "sup" gives the area of the insured field in the harvest branch. The "Assured Value" data reflects the CFA franc value of the insured asset. "NS" gives the number of losses suffered by any policy. "MS" gives the cost of the claim. The variable "type of loss" gives the nature of the claim and includes 19 terms.

\subsection{The Variables of the Model}

The variables selected are nine (9) including two endogenous variables (the number of claims and the average cost of a claim) and seven exogenous variables, five of which are dichotomous (1: if the risk was realized on the insured and 0 : otherwise) and a quantitative in this case the area.

\subsubsection{Types of Risks}

\section{1) Wild Animals (AS)}


Man and wildlife are increasingly competing for living space, increasing the risk of conflict, threats to human lives and livelihoods. Agricultural areas, with their varied grasslands and crops, exert a strong attraction on wildlife, especially if they are close to quiet areas such as hedges, wastelands, woods or forests. The food is plentiful and the inconvenience is minimal. This coexistence between agricultural activity, for economic purposes, and the frequentation by the wildlife does not often pose the problem of the damage only in case of overpopulation of the latter.

The extent of damage to agricultural production is in complex relation with the dynamics and density of local population, the diet and the body size of the responsible species, as well as with the capacity of reception of the environment.

2) Wild duck (CS)

Damage caused by waterbirds in crops is high. Farmers know the risk, but cannot predict the location of the damage, although the risks are higher at the center of the trap, near a pond for example, than at the edges. , or in case of delay in the drainage of rice fields or in the vicinity of faults in the crop (free water spots). In fact, the risk of damage to ducks is similar to that of hail in temperate countries or the risk of migrating locusts in tropical areas

Finally, the perception of the damage is more acute if the harvests are bad: the pests then take an indispensable part of the food of the peasants and their family and not only a part of the surplus of harvest when the cultivation conditions (pluviometry, floods) have been good.

\section{3) Rainfall deficit (DP)}

In most Sahelian countries, rainfall deficit agricultural production. Vegetation is at risk of rapid degradation due to overexploitation. For many years, many regions have suffered from an exceptional rainfall deficit. Any form of drought comes from a rainfall deficit. This dependence weakens the Senegalese economy and makes it vulnerable to fluctuating commodity prices and rainfall deficits. However, it is possible that the level of production is barely average in some regions, especially those with a rainfall deficit.

\section{4) Flood (INOND)}

A flood is a temporary flood, natural or artificial, of a space by water. Flooding is one of the main natural hazards in the world; it is the natural disaster causing the most damage to the crops. During flooding, we also face disturbances and losses in food production. A difficult situation for farmers, especially since there is no flood insurance.

\section{5) Health risks (RS)}

The exact contours of the health risk are difficult to pin down. Diseases (animal and plant) are obviously part of it. Pests (insects, nematodes, rodents, etc.) can also be attached to them. The same is true for micro-organisms and chemical substances that, when they exceed a certain threshold, threaten the food security of consumers, even if they do not lead to a quantitative loss of production, or even a decline in production. The apparent quality of the products. Unlike 
weather hazards, most of these phenomena are, at least in part, controllable by the farmer; on the other hand, new risks appear regularly. Plant diseases can also be divided into two groups: 1) "exceptional" diseases, in which there is no effective treatment and against which it can only be controlled by destroying the infected plants; 2) "common" pathologies which, occasionally, can lead to substantial production losses but which can be controlled by curative or preventive treatments.

\section{6) Desert Locust (CP)}

Locust swarms have for centuries been a threat to agricultural production in West Africa. The livelihoods of the population may be affected by this voracious insect. The Desert Locust is potentially the most dangerous locust pest because of the ability of swarms to fly rapidly over long distances. It is two to five generations a year.

\section{7) The area (SUP)}

The area used by farmers has an impact on the frequency of agricultural claims. Indeed the more the cultivated area increases the more the number of claims will tend to increase.

8) Aphid Invasions (IP)

Aphid colonies cause a major weakening of plants and are vectors of a large number of plant viruses. These viruses can lead to plant death or the development of a large number of deformities of leaves, stems, or flowers. They are most often considered as harmful.

\subsubsection{Endogenous Variables}

The modeling focuses on two variables: the number of claims and the average cost of a claim.

\section{1) The number of claims (NS)}

The number of claims is the number of times the insured has suffered a particular claim. The number of claims is a count variable.

\section{2) The average cost of the incident (CMS)}

The average cost of the claim is the indemnity paid by the insurer following the realization of a given type of claim. The average cost of the claim is a variable belonging to $\mathrm{R}+$.

\subsection{Specification}

\subsubsection{Modeling of the Frequency}

The law of Poisson is a law that applies to the modeling of phenomena whose occurrence is not very frequent or rare compared to the size of the population concerned. Events within the study population must be independent. Poisson's law is fundamental in modeling the number of claims for property and casualty insurance risks. It is in a way the basic law.

$$
N \sim \operatorname{Pois}(\lambda)
$$

The law of probability is written: 


$$
P[N=k]=\left(\lambda^{k} \cdot \exp (-\lambda)\right) / k !
$$

where

$$
k !=k \cdot(k-1)(k-2) \cdot 2 \cdot 1
$$

And

$$
k=0,1,2,3,4, \cdots
$$

For the Poisson's law $E(N)=V(N)$. This property is called equi-dispersion. When equi-dispersion is not respected, that is to say, when we have an overdispersion, we consider a quasi-Poisson law, such as $\operatorname{Var}(N \mid X)=\varphi E(N \mid X)$, where $\varphi$ dispersion parameter. It is a parameter to estimate. Under certain assumptions it is shown that the process of the number of claims is a Poisson process. The law of Poisson can be constructed from a single hypothesis: the probability of occurrence of a disaster in the near future is proportional to the envisaged duration and does not depend on past observations. It also has the advantage of requiring only one parameter 1 . The law of Poisson is therefore of "natural" use in insurance.

$$
\begin{gathered}
E(X)=E(K) \cdot E(Y) \\
V(X)=E(K) \cdot V(Y)+V(K) \cdot E^{2}(Y)=V(K) \cdot E^{2}(Y)
\end{gathered}
$$

The purpose here is to determine whether the ratio of the number of patients to the number of exposures, $n_{i} / N_{i}$ is approximately constant or not according to risk. We suppose that the count $Y_{i}=n_{i}$ follows a mean Poisson distribution:

$$
\mu_{i}=N_{i} \cdot \exp \left(\alpha_{0}+\alpha_{1} X_{1 i}+\alpha_{2} X_{1 i}+\alpha_{3} X_{1 i}+\cdots+\alpha_{p} X_{p i}\right)
$$

The studied model is written thus:

$$
\begin{gathered}
Y_{i} \sim \operatorname{Poisson}\left(\mu_{i}\right) \\
\log \left(\mu_{i}\right)=\log \left(N_{i}\right)+\alpha_{0}+\alpha_{1} X_{1 i}+\alpha_{2} X_{1 i}+\alpha_{3} X_{1 i}+\cdots+\alpha_{p} X_{p i}
\end{gathered}
$$

The regression model derived from the law of Poison taking into account the risk variables is written as follows:

$$
\log (\mathrm{NS})=\alpha_{0}+\alpha_{1} \mathrm{CS}+\alpha_{2} \mathrm{AS}+\alpha_{3} \mathrm{DP}+\alpha_{4} \mathrm{INOND}+\alpha_{5} \mathrm{RS}+\alpha_{6} \mathrm{CP}+\alpha_{7} \mathrm{SUP}
$$

\subsubsection{Modeling the Average cost of Claims}

\section{1) The normal log law}

The normal log law is a law that allows modeling of approximately symmetrical or asymmetric data to the right. A random variable $X$ follows a normal log law when its logarithm follows a normal distribution. The probability density of this law is written as follows:

$$
f(x)=1 / x 1 /(\beta \sqrt{2 \pi}) \exp \left(-1 / 2((\ln (x)-\alpha) / \beta)^{2}\right), x>0
$$

With

$$
\begin{aligned}
& \alpha=E(\ln (X)) \text { Espérance mathématique de } \ln (X) \\
& \text { And } \\
& \beta=\sigma_{\ln (X)} \text { Ecart type de } \ln (X)
\end{aligned}
$$


Hence the moments of the random variable $\mathrm{X}$ are:

$$
\delta_{X}=E(X)=\exp \left(\left(\delta_{\ln (X)}+\sigma_{\ln (X)}\right)\right) / 2
$$

The variance is:

$$
\sigma_{x}^{2}=V(X)=\exp \left(2\left(\delta_{\ln (X)}+\sigma_{\ln (X)}^{2}\right)\left(\exp \left(\sigma_{\ln (X)}^{2}-1\right) / \exp \left(\sigma_{\ln (X)}^{2}\right)\right)\right)
$$

The average cost regression model derived from log-normal, taking into account risk variables, is as follows:

$$
\begin{gathered}
C M_{i} \sim \operatorname{lognormale}\left(\delta_{x}\right) \\
\log (C M)=\beta_{0}+\beta_{1} \mathrm{~S}+\beta_{2} \mathrm{AS}+\beta_{3} \mathrm{DP}+\beta_{4} \mathrm{INOND}+\beta_{5} \mathrm{RS}+\beta_{6} \mathrm{CP}+\beta_{7} \mathrm{SUP}
\end{gathered}
$$

\section{2) The Gamma Law}

A real random variable follows a gamma law of parameters $\gamma$ and a, if and only if its probability density is given by the following formula:

$$
f(x)=\left(\gamma^{a} / \Gamma(a)\right) \cdot x^{a-1} \cdot \exp (-\gamma x), x \geq 0
$$

Hence the moments of the real random variable $\mathrm{X}$ are:

The average:

$$
\theta_{x}=E(X)=a / \gamma
$$

The variance

$$
\sigma_{x}=V(X)=a / \gamma^{2}
$$

\section{Econometric Estimation and Interpretation of Results}

\subsection{Adjustment Test}

The quantile-quantile diagram allows a graphical appreciation of the fit of an observed distribution to a theoretical model. On this graph, the y-axis carries the quantiles $\mathrm{i} x$ of the observed distribution, while the $\mathrm{x}$-axis carries the corresponding quantiles of the theoretical law. The cloud of points align with the first bisector when the proposed theoretical distribution is a good representation of the observations. It should be noted that the appreciation of the alignment of points along the bisector can be considered subjective. All the deviations from the alignment (ends with curvature, distant points) can be identified and analyzed.

Quantile-quantile diagrams are plotted for any adjustment by a continuous law whose distribution function is strictly increasing, that is to say a law whose distribution function is bijective over the interval corresponding to non-zero values of the density function and not having "holes". We will show the application for normal, log-normal and gamma laws etc.

The histograms show the average cost of claims adjusted to a law, if the distribution of the variable is consistent with the curve of each of the predetermined laws (Figure 1). The chart below tests the distribution to which the average cost for difference law adjusts. We find that the average cost adjusts to the 


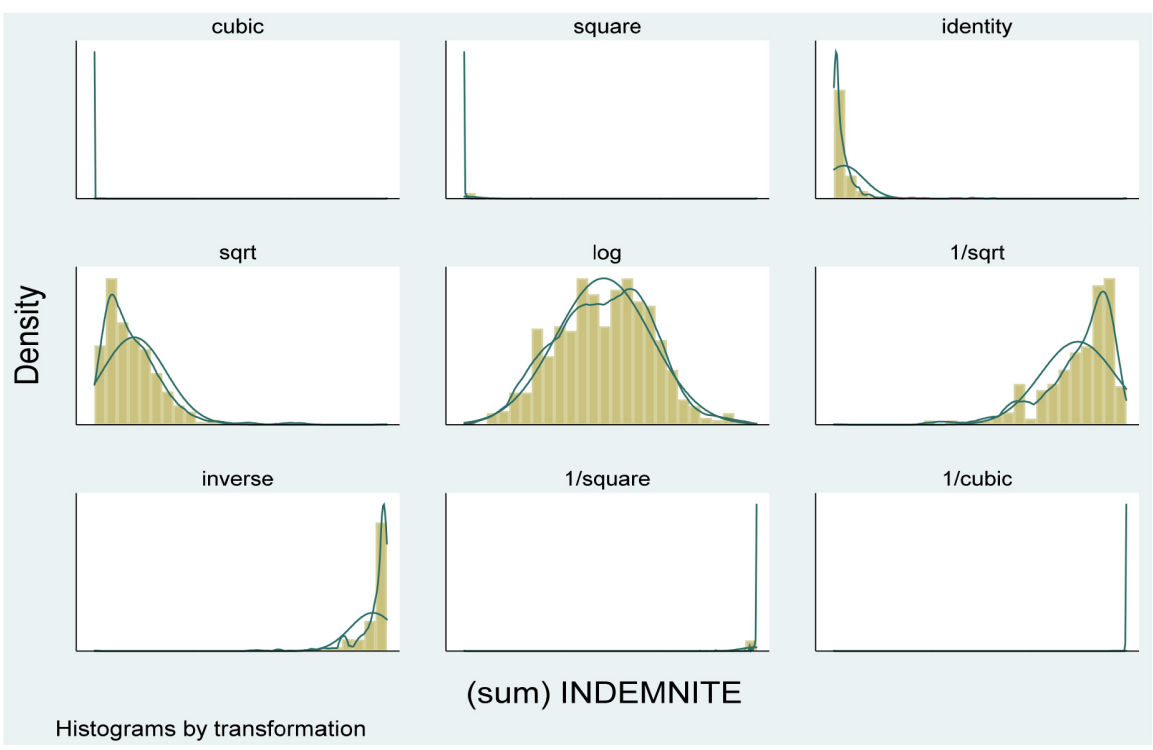

Figure 1. Disaster distribution.

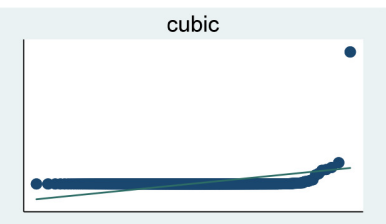

sqrt

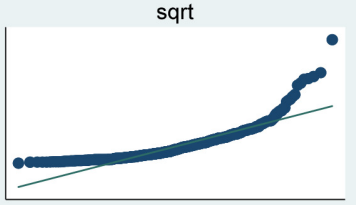

inverse

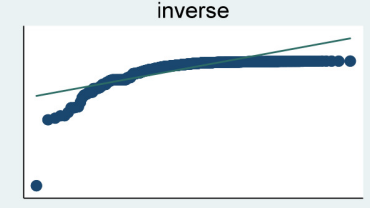

Quantile-Normal plots by transformation

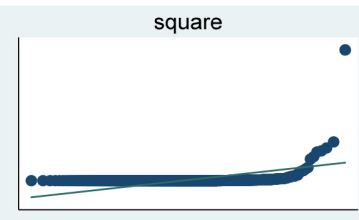

$\log$

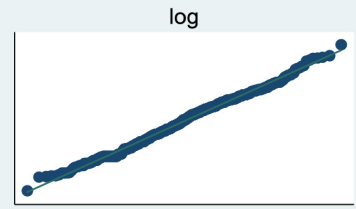

$1 /$ square

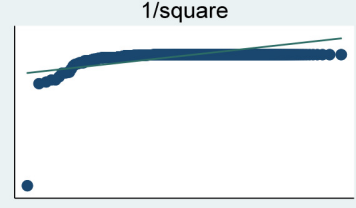

(sum) INDEMNITE
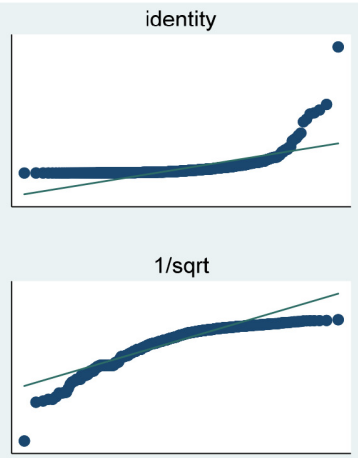

1/cubic

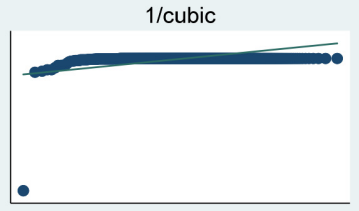

Figure 2. Empirical and theoretical quantile diagram.

log-normal law and the gamma law.

To determine if the data follows a log-normal or gamma law, we compare the QQ-Plot diagrams (Figure 2). The regression on a plane of the empirical and theoretical quantiles of the different distributions shows that the average distribution of costs adjusts to the gamma and lognormal distribution.

The adequacy tests carried out by comparing the distribution functions lead to the conclusion that the average cost of claims also depends on several other variables.

Indeed, the regressions between the theoretical and empirical quantiles show that almost all the points are on the first bisector. This shows the empirical dis- 
tribution of the average cost of claims corespond to the theoretical distributions (log-normal and gamma).

\subsection{The Empirical Model}

Three models are estimated, a Poisson model for the frequency of claims, a lognormal model and a gamma model for the average cost of a claim (see Table 2). We have taken as a reference the risk "accident". The parameters of the three models are estimated by maximum likelihood and the estimation of the variance-covariance matrix of the parameters leads to the pseudo-likelihood. The likelihoods of the three models are obtained respectively after three, four and six iterations and are equal to $-1471.38 ; 7331.83 ;-6714.70$.

For the Poisson model, the chi-square Wald statistic with seven degrees of freedom for the full model, allows us to test whether all the estimated coefficients are equal to zero. From the value p, we can see that the model is statistically significant. The coefficients of the model are all significant at $1 \%$. The pseudo-R2 is equal to 0.18 .

Table 2. Econometrics estimations.

\begin{tabular}{|c|c|c|c|}
\hline Variables & Number of claim & $\begin{array}{l}\text { Sinister cost } \\
\text { Log-normal }\end{array}$ & $\begin{array}{c}\text { Sinister cost } \\
\text { Gamma }\end{array}$ \\
\hline \multirow[t]{2}{*}{ Surface area } & $0.340^{\star * *}$ & $0.579^{* * *}$ & $0.682^{\star * *}$ \\
\hline & $(0.0745)$ & $(0.0518)$ & $(0.0323)$ \\
\hline \multirow[t]{2}{*}{ Wild animals } & $0.401^{\star * *}$ & $1.645^{* * *}$ & $1.275^{\star \star \star}$ \\
\hline & $(0.108)$ & $(0.441)$ & $(0.118)$ \\
\hline \multirow[t]{2}{*}{ Wild ducks } & $1.425^{\star \star \star}$ & $0.863^{\star * *}$ & $1.104^{\star * *}$ \\
\hline & $(0.306)$ & $(0.135)$ & $(0.131)$ \\
\hline \multirow[t]{2}{*}{ Desert Locust } & $0.848^{\star * *}$ & $1.921^{\star \star *}$ & $2.255^{\star \star *}$ \\
\hline & $(0.199)$ & $(0.175)$ & $(0.177)$ \\
\hline \multirow[t]{2}{*}{ Rainfall deficit } & $1.648^{\star * *}$ & $0.520^{* *}$ & $0.803^{* * *}$ \\
\hline & $(0.455)$ & $(0.202)$ & $(0.260)$ \\
\hline \multirow[t]{2}{*}{ Flood } & $2.585^{\star \star \star}$ & $1.323^{\star * *}$ & $1.268^{\star * *}$ \\
\hline & $(0.366)$ & $(0.388)$ & $(0.239)$ \\
\hline \multirow[t]{2}{*}{ Sanitary risks } & $1.872^{* * *}$ & $1.862^{* * *}$ & $3.260^{* * *}$ \\
\hline & $(0.561)$ & $(0.547)$ & $(0.288)$ \\
\hline \multirow[t]{2}{*}{ Grain-eating birds } & $1.094^{\star * *}$ & $1.974^{\star * *}$ & $1.898^{\star * *}$ \\
\hline & $(0.114)$ & $(0.0993)$ & $(0.0599)$ \\
\hline \multirow[t]{2}{*}{ Constant } & $-0.872^{* * *}$ & $10.11^{* * *}$ & $9.842^{* * *}$ \\
\hline & $(0.191)$ & $(0.133)$ & $(0.0829)$ \\
\hline Observations & 491 & 491 & 491 \\
\hline Family & Poisson & Log-norm & gamma \\
\hline Link & $\log$ & gaussian & $\log$ \\
\hline Deviance & 1770.61 & $2.911 \mathrm{e}+14$ & 401.51 \\
\hline Pearson & 2997.77 & $2.911 \mathrm{e}+14$ & 407.75 \\
\hline Loglik & -1471.38 & -7351.83 & -6714.70 \\
\hline AIC & 6.02 & 29.97 & 27.38 \\
\hline BIC & -1222.27 & $2.91 \mathrm{e}+14$ & -2591.36 \\
\hline
\end{tabular}

Source: NCIAS database/Author. 
The coefficients of the Poisson regression for each of the variables, as well as standard errors, are robust and are shown in the table below. The coefficient for the area is 0.34 . This means that increasing the cultivated area by $10 \%$ leads to an increase in the number of claims by $3.4 \%$. The coefficient for the variable "wild animals" is the expected difference between this risk and the reference risk (Aphid Invasions). Compared with aphid invasions, the log of the number of expected casualties with wild animals increases by approximately 0.401 . The number of claims increases by $\exp (0.401)=1.493$. For wild ducks, the log number of claims increased by 1.425 , giving rise to 4.15 claims. For locusts, we note an increase of $0.848 \mathrm{log}$ of the number of claims or 2.33 claims. The log of the rainfall deficit records a 1.648 or 5.196 claims. The loss ratio is very high with the floods. Indeed, an increase in the log of the accident number of $2.585 \mathrm{com}$ pared to accidents is recorded, ie 13.26 claims. For diseases, the log number of claims increased by 1.872 , reflecting an increase in the number of claims compared to accidents at $\exp (1.872)=6.50$.

To choose between two models (gamma and log-normal). We will use the deviance statistics, the Pearson statistic, and the AIC and BIC criteria of both models. Pearson's deviance and statistics are measures of the quality of fit of a generalized linear model. Or rather, it's measures of the wrong fit. Higher values indicate an adjustment. We note that the deviance and the Pearson statistic of the log-normal law are higher than those of the gamma law. In addition, the values of the AIC and BIC criteria for the gamma law are lower than those of the lognormal law. Therefore we have opted for the model of the gamma law presented by the table above. So our model is written as:

$$
\begin{aligned}
E[\log C M]= & 9.842+1.104 \times \mathrm{CS}+1.275 \times \mathrm{AS}+0.803 \times \mathrm{DP} \\
& +1.268 \times \mathrm{INOND}+3.260 \times \mathrm{RS}+2.255 \times \mathrm{CP}+0.682 \times \mathrm{SU}
\end{aligned}
$$

From the above equation it can be deduced that farmers exposed to health risks, desert locusts and grain-eating birds have a greater risk of loss-making than others. Therefore, if an insured suffers a health risk, his log-cost expectation increases by 3.26 compared to an aphid invasion, so his cost is multiplied by exp (3.26) = 26.049. Conversely, if an insured person exposes himself to Desert Locusts, the expectation of his increases by 2.25 , so his cost is multiplied by $\exp (2.25)=9.48$ compared to an invasion of aphids. For policyholders invading grain-eating birds, the cost logarithm increases by 1.898, a multiplication of the cost of $\exp (1.898)=$ 6.72 compared to an accident. Exposure to wild animals increases the logarithm of the cost of 1.275, a multiplication of the cost of 3.578. Flooding causes a multiplication of the cost of 3.553, wild ducks 3.016; the rainfall deficit of 2.232. In terms of area, a $10 \%$ increase in area leads to an increase in the cost of $6.82 \%$.

In conclusion, we note that the health risks, locust invasions (Desert Locust), wild animals and ducks have higher claims than climatic events (rainfall deficits, floods).

\subsection{Determination of the Pure Premium}

The pure premium is determined by multiplying the probability of loss by the 
Table 3. Pure premium.

\begin{tabular}{cccccc}
\hline Risks & $\begin{array}{c}\text { Average } \\
\text { cost }\end{array}$ & $\begin{array}{c}\text { Prob } \\
(\mathrm{n}=2)\end{array}$ & Expectation & $\begin{array}{c}\text { Grants } \\
(50 \%)\end{array}$ & $\begin{array}{c}\text { Premium } \\
\text { to pay }\end{array}$ \\
\hline Wild animals & 348,947 & 0.192 & 67,141 & 33,570 & 33,570 \\
Wild ducks & 252,567 & 0.191 & 48,157 & 24,079 & 24,079 \\
Desert Locust & 190,409 & 0.183 & 34,824 & 17,412 & 17,412 \\
Rainfall deficit & 100,430 & 0.197 & 19,817 & 9909 & 9909 \\
Flood & 225,490 & 0.033 & 7500 & 3750 & 3750 \\
Aphid invasions & 108,000 & 0.184 & 19,865 & 9933 & 9933 \\
Sanitary risks & $3,416,935$ & 0.020 & 67,919 & 33,960 & 33960 \\
Grain-eating birds & 614,873 & 0.224 & 137,425 & 68,712 & 68,712 \\
Risk & Average & Prob & Expectation & Grants & Premium \\
Wild animals & cost & $(\mathrm{n}=1)$ & $50 \%)$ & to pay \\
Wild ducks & 348,947 & 0.327 & 114,206 & 57,103 & 57103 \\
Desert Locust & 252,567 & 0.160 & 40,478 & 20,239 & 20239 \\
Rainfall deficit & 190,409 & 0.366 & 69,644 & 34,822 & 34,822 \\
Flood & 100,430 & 0.123 & 12,359 & 6179 & 6179 \\
Aphid invasions & 225,490 & 0.014 & 3215 & 1607 & 1607 \\
Sanitary risks & 108,000 & 0.368 & 39,731 & 19,865 & 19,865 \\
Grain-eating birds & $3,416,935$ & 0.006 & 18,964 & 9482 & 9482 \\
\hline
\end{tabular}

Source : NACIS database/autor.

cost of the loss (Table 3 ). If the premium is subsidized by $50 \%$, the net premium to be paid by the insured is given in the last column of the table. We found that Desert Locusts, grain-eating birds, wild animals and wild ducks are the most common. The pure premium varies according to the risk to which the insured is exposed.

The pure premium is evaluated for invasions at 68,873 CFA francs for carnivorous birds, 57,103 for wild birds, 20,239 for wild ducks, 34,822 for desert locusts, and 19,865 for aphids, respectively. In terms of climatic phenomena such as floods and precipitation deficits, the pure premiums are estimated at 1607 CFA francs and 6179 respectively, while the health risks are 9482 CFA francs.

Health risks, floods and rainfall deficits are extreme phenomena whose probability of achievement is low. This explains the low premiums of these risks.

\section{Conclusions}

The purpose of this article was to determine the pure premium to be paid by the Senegalese farmer insured at conventional risks. Using the general linear model (GLM), the frequency and severity of different types of risks to farmers were determined. They depend positively on the type of risk and the parameters of the estimated models are all significant. We have shown that the health risks, locusts 
(wild locusts), wild animals and ducks have higher claims than climatic events (rainfall deficit, floods). Health risks, floods and rainfall deficits are extreme phenomena whose probability of achievement is low. This explains the low premiums of these risks. For better pricing, the insurance company will need to consider the type of risk to which each insured is most exposed and determine the corresponding premium. This segmentation will determine the correct premium.

This study has some limitations: other risks such as bushfires, drought and performance risk could be incorporated as variables in the model; here the aggregated cost of claims is considered.

In order to improve this model, we propose to add to the model the variables, such as: the geographical area (region, department, etc.), the client's claims history, as any customer is likely to suffer a similar loss. A previously committed; the density of the fields in the region because it is obvious that the probability of disaster of a customer living in a zone with a lot of fields is greater than that of a customer living in an area where the fields are few. Another proposed improvement perspective is to combine several predictive analysis algorithms to make the predictions and not rely solely on the generalized linear regression.

This study could be improved by determining the pure premium depending on each type of crop and the risks to which the crop is exposed. The pure premium could also be determined based on the yield deficit. Indeed, the fixing of a reference yield calculated from, for example, the yields observed over the last five years and set as a trigger, would make it possible to calculate the loss suffered by the farmer if his yield for a given crop is below the reference.

\section{Conflicts of Interest}

The author declares no conflicts of interest regarding the publication of this paper.

\section{References}

[1] Bühlmann, H. (1969) Experience Rating and Credibility. ASTIN Bulletin, 5, 157165. https://doi.org/10.1017/S0515036100008023

[2] Miranda Mario, J. (1991) Area-Yield Crop Insurance Reconsidered. American Journal of Agricultural Economics, 73, 233-242. https://doi.org/10.2307/1242708

[3] Williams, J., Carriker, G.L., Art Barnaby, G. and Harper, J.K. (1993) Crop Insurance and Disaster Assistance Designs for Wheat and Grain Sorghum. American Journal of Agricultural Economics, 75, 435-447. https://doi.org/10.2307/1242928

[4] Treerattanapun, A. (2011) The Impact of Culture on Non-Life Insurance Consumption. University of Pennsylvania, Philadelphia.

[5] Fazelbeigi, M.M. and Yavari, G.R. (2010) An Analysis of Challenges Faced by Crop Insurance Fund in Iran. Rural Areas \& Development, 13, 21-41.

[6] Claassen, R., Carriazo, F., Cooper, J.C., Hellerstein, D. and Ueda, K. (2011) Grassland to Cropland Conversion in the Northern Plains: The Role of Crop Insurance, Commodity, and Disaster Programs. USDA, Economic Research Service, Economic 
Research Report 120.

https://ageconsearch.umn.edu/record/262239/files/7477_err120.pdf

[7] Miao, R., Feng, H. and Hennessy, D.A. (2011) Land Use Consequences of Crop Insurance Subsidies. Annual Meeting of the Agricultural and Applied Economics Association, Pittsburgh, 24-26 July 2011, 1-52.

[8] Smith, V.H. and Goodwin, B.K. (1996) Crop Insurance, Moral Hazard, and Agricultural Chemical Use. American Journal of Agricultural Economics, 78, 428-438. https://doi.org/10.2307/1243714

[9] Babcock, B.A. and Hennessy, D.A. (1996) Input Demand under Yield and Revenue Insurance. American Journal of Agricultural Economics, 78, 416-427.

https://doi.org/10.2307/1243713

[10] Horowitz, J.K. and Lichtenberg, E. (1993) Insurance, Moral Hazard, and Chemical Use in Agriculture. American Journal of Agricultural Economics, 75, 926-935. https://doi.org/10.2307/1243980

[11] Nwosu, F.O., Oguoma, N.N.O., Lemchi, J.I., Ben-Chendo, G.O., Henri-Ukoha, A., Onyeagocha, S.U.O. and Ibeawuchi, I.I. (2012) Output Performance of Food-Crop Farmers under the Nigerian Agricultural Insurance Scheme in Imo State, South East, Nigeria. Academia Arena, 2, 43-47.

[12] Adisak, P., Sukuman, S. and Thiradet, J. (2010) Mathematical Modelling for the Estimation of Crop Insurance Premium: A Case Study of Total Premium Equal Damage Compensation. King Mongkut's University of Technology, Thonburi.

[13] Gideon, D., Kwabena, N. and Dennis, E. (2014) Willingness to Pay for Farm Insurance by Smallholder Cocoa Farmers in Ghana. Journal of Social Science for Policy Implications, 2, 163-183.

[14] Alba, C., Antonio, S., Inés, M. and Alberto, G. (2017) Crop Insurance Demand in Wheat Production: Focusing on Yield Gaps and Asymmetric Information. Spanish Journal of Agriculture Research, 15, e0119. https://doi.org/10.5424/sjar/2017154-10716

[15] Zelda, A., Godwell, N. and Michael, A. (2018) Effects of Climate Variability and Insurance Adoption on Crop Production in Select Provinces of South Africa. Journal of Water and Climate Change, 9, 500-511. 